\title{
Designing with Care
}

\author{
Yvonne Schikhof ${ }^{1,2}$, Ingrid Mulder ${ }^{2,3}$, Martijn Vastenburg ${ }^{3}$ \\ ${ }^{1}$ School of Health Care Studies \\ ${ }^{2}$ School of Communication, Media \& IT \\ Rotterdam University of applied science \\ Rotterdam, The Netherlands \\ y.schikhof@hro.nl, mulderi@acm.org \\ ${ }^{3}$ ID-StudioLab \\ Faculty of Industrial Design Engineering \\ Delft University of Technology \\ Delft, The Netherlands \\ M.H.Vastenburg@,tudelft.nl
}

\begin{abstract}
Humane care asks for designing with care and designing with users and other stakeholders at heart. The focus of the workshop is on human values in relation to pervasive technology and the outcome will be a research agenda for the nearby future.
\end{abstract}

Keywords-human values; user involvement; design methods

\section{INTRODUCTION}

In establishing humane care next to understanding the context of use, understanding human values is a key factor towards creating acceptable pervasive healthcare applications. In order to avoid dehumanizing and stigmatizing the user, we plea to involving humans and incorporate their values in the design approach. This is especially true for designing pervasive healthcare applications, where the 'complexity of users' is increasingly sensitive. By considering human values in the design process, designers and developers can create pervasive health applications that better fit the end user needs and desires. Incorporating values into design can also reduce the resistance to new technology.

\section{ABOUT THE TOPIC}

Healthcare technologies are increasingly pervasive, moving into the working environment of health care professionals and homes of the patients, presenting new challenges to design and evaluation of pervasive healthcare applications. The complexity and scope of pervasive health care has brought together practitioners from a wide range of disciplines. Experience has shown that design and evaluation of pervasive systems is extremely difficult. Approaches tend to be subjective, piecemeal or both. Individual approaches to evaluation risk being incomplete and comparisons between systems can be difficult $[1,3]$. Participation of end users in the design process tends to be limited, and evaluation tends to be subjective, limited in time and in an unrealistic setting, resulting in findings with limited validity. Although these challenges are faced when designing pervasive systems in general, designing and evaluating pervasive health applications face additional challenges; these applications are increasingly perceived as useful for a diverse group of 'non typical' users including older and disabled people. Whereas user centered design strives to involve the direct (end) users in the design trajectory, user centered design for healthcare refers to these 'non-typical' users, who have diverse backgrounds, skills, living conditions, abilities, needs and desires and who can be hard to reach. Although the vital importance of ensuring that the healthcare technology is usable, appropriate and acceptable for these groups has been widely researched, recognition of incorporating human values in the design is only now beginning. For example, regarding the adoption of innovative technology in the health care domain, there is hardly any attention paid to ethical issues in healthcare technology projects other than discussing these issues while implementing a new technology, for instance in informing the health care professionals shortly before introducing a new system $[2,4]$.

\section{ABOUT THE WORKHSOP}

The workshop aims to provide insights that contribute to the design methodology of pervasive healthcare technology in terms of creating a consistent set of methods and guidelines for design and evaluation of pervasive health applications. The focus will be on human values in relation to pervasive technology. We particularly invite people to share their experiences in dealing with incorporating values into the design of pervasive health systems and / or best practices understanding the sensitive issues facing when designing for the health domain.

The objective of this workshop is to bring together researchers, designers and practitioners - with a clear interest in the areas of human centered design and evaluation and pervasive technologies for healthcare - that contribute to a vivid discussion leading to improved methods and tools that cope with human values in designing pervasive health applications with care.

Topics addressed in the workshop include, but are not limited to:

- User involvement when end users are hard to reach

- Evaluation of pervasive healthcare applications

- Design methods and techniques

- Value-sensitive design

- Technology acceptance

- Ethical issues

- Diagnosis and monitoring practices of (chronic) patients 


\section{A. Workshop Format}

The one-day workshop will be organized around a series of best practices and cases, through which we will discuss how to conduct evaluations which allow assessment of human values and ethical issues in its context of use. We will use the first session to introduce participants (via brief talks of about 5 minutes), which will be followed by an initial round of discussion. One outcome of this discussion will be the (sub-)set of questions to be discussed more thoroughly in small groups.

During the second session, we will break up into groups of about 5 members each to discuss the previously identified questions in-detail and aim to get more insight in 1) incorporating values in the human centered design approach and 2) applying methods and tools for understanding the context. When necessary, selected cases will be used to stimulate the discussion.

In the third session the individual groups will report on their discussions and give feedback on the selected cases. The workshop will conclude with a plenary discussion of the issues raised and points made. We will decide how to proceed with the topic in general, aiming to establish a research agenda.

\section{B. Expected Outcome}

The first outcome of this workshop is community building for researchers and practitioners interested in involving users and incorporating human values in the design and evaluation of pervasive healthcare applications. Second, a research agenda including research questions, evolving directions and relevant methods and techniques to designing and evaluating pervasive healthcare application with care, will be established. Workshop participants are encouraged to extend their position papers and contribute to a special issue 'designing with care'. We are planning to have this special issue published with Springer Journal Ethics and Information Technology. This will be the main publication reflecting the discussions of this workshop, although the call will be open to others.

\section{Workshop Chairs}

Yvonne Schikhof, Rotterdam University

Ingrid Mulder, Rotterdam University

Martijn Vastenburg, Delft University of Technology

\section{Program Committee}

Jeroen van den Hoven, Delft University of Technology (Program Chair)

Ann Ackaert, University of Gent

Anneloes Cordia, Rotterdam University

Alois Ferscha, University of Linz

Vlado Glavinic, University of Zagreb

Marleen Goumans, Rotterdam University

Anne Gross, Fraunhofer Institute

Andreas Hochgatterer, Austrian Research Centers

David Keyson, Delft University of Technology

Andreas Komninos, Glasgow Caledonian University

Helianthe Kort, Utrecht University of Applied Science

Christian Kray, University of Newcastle

Julie Maitland, University of Glasgow

Andrew Monk, University of York

Birgit Morlion, IBBT, Belgium

Katie Siek, University of Colorado, Boulder

Graeme Stevenson, University College Dublin

Maarten Wegdam, Telematica Instituut \& Twente University

\section{REFERENCES}

[1] Neely, S., Stevenson, G., Kray, C., Mulder, I., Connelly, K., \& Siek, K.A. (2008). Evaluating Pervasive and Ubiquitous Systems. IEEE Pervasive Computing, 7(3), (July-Sept 2008), pp. 85-88.

[2] Schikhof, Y. \& Mulder, I. (2008). Under watch and ward at night: design and evaluation of a remote monitoring system for dementia care. In: A. Holzinger (Ed.). USAB 2008 - Usability \& HCI for Education and Work, LNCS 5298 (pp. 475-486). Springer-Verlag: Berlin Heidelberg.

[3] Siek, K.A., Neely, S., Stevenson, G., Kray, C. \& Mulder, I. (eds.). Advances in Evaluating Mobile and Ubiquitous Systems, Special issue (April-June 2009). International Journal of Mobile Human Computer Interaction (IJMHCI), I(2).

[4] Vastenburg, M.H., Visser, T., Vermaas, M. \& Keyson, D.V. (2008) Designing Acceptable Assisted Living Services for Elderly Users. In: E. Aarts et al. (eds.). Ambient Intelligence, LNCS 5355 (pp. 1-12). Springer-Verlag: Berlin Heidelberg. 